THE APPROACHING REVISION of

\section{THE BRITISH PHARMACOPEIA.} I.

FROM A PRESCRIBER'S POINT OF VIEW.

By T. LAUDER BRUNTON, M.D., D.Sc.Edin., LL.D.Hon. ABERD., F.R.C.P., F.R.S.,

Lecturer on Pharmacology and Therapeutics, and Assistant Physician to St. Bartholomew's Hospital, London.

The Scope and Objects of the "British Pharmacopcia."-Redundancies and Deficiencies.-Solubility and Compatibility.Prescribing Difficulties and the Increase of Proprietary Preparations.-Pills and Granules.-A Complicated Poultice.Dosage.

THE announcement that a new edition of the British Pharmacopaia is in preparation naturally leads every one who is interested either in the administration or preparation of medicines to ask what changes are likely to be made in it so as to make it more useful or more convenient. The object of the Pharmacopoia is thus stated in the preface to the edition of 1867. "It is intended to afford to the members of the medical profession and those engaged in the preparation of medicines throughout the British Empire, one uniform standard and guide whereby the nature and composition of substances to be used in medicine may be ascertained and determined," From the definition thus given by the General Medical Council, it is evident that the scope of the British Pharmacopoia is very wide indeed, whether we regard the number of practitioners and chemists whom it is intended to help, and who must be numbered by tens of thousands, or the extent over which its influence will spread -and this is no less than an empire on which the sun never sets, or the number of people whose health and lives it is intended to safeguard-and these are to be numbered by hundreds of millions.

It is not my intention here to speak of the British Pharmacopoeia in its relation to the enormous part of the British Empire which lies outside of Great Britain and Ireland, nor of its use by pharmaceutical chemists and dispensers, but only of its use to the prescriber. The medical profession has much cause to thank the General Medical Council for the unification of the London. Dublin, and Edinburgh Pharma. copoias; but, notwithstanding the time and labour that have been expended upon the British Pharmacopoeia in successive editions it is still far from perfect, and much more may still be done in the way of rendering it useful to the medical man. He it is for whom the book is primarily intended. It is a work issued by the General Medical Council as a standard and guide to the members of the medical profession, and only secondarily to chemists and pharmacists. This is seen by the fact that the latter have no direct voice in the preparation of the Pharmacopoia, and have only been called in to give advice when required. Yet in the consulting rooms and libraries of doctors in general the British Pharmacopoia is generally conspicuous by its absence, so much so that one is often tempted to ask who have bought up the thousands of copies issued by the General Medical Council.

But while comparatively few medical men possess a British Pharmacopcia, nearly every one has got either Squire's Companion or Martindale and Westcott's Extra Pharmacopoeia, or both, and it may be worth while to inquire why it is that these works enjoy so much greater a popularity than the British Pharmacopaia. One reason probably is that they give less, and another that they give more than the official publication. They give less because they leave out the methods of preparing the various substances which no medical man or dispensing chemist ever dreams of making, and they give more, inasmuch as they supply useful information about the preservation of medicines and different modes of prescribing them in a more or less agreeable form, as well as hints, or even fairly full statements about their action and uses. Thus, if we turn to such a common article as chloroform in the Pharmacopoia, we find that the greatest part of the space allotted to it is taken up by an elabcrate description of how to make it. This is of no use to either dispensing chemists or to medical men, for they both purchase their chloroform from well-known firms who manufacture it on a large scale. But no hint is given of the advisability of keeping it in a dark place, although the advisability of keeping it cool is mentioned. On turning to ether, we again tind a long process for making it, but not a word is said about keeping it in a cool place away from lights or fire, so as to avoid the possibility of an explosion or conflagration. Under collodion we find mention of the inflammability of the liquid, but nothing about the necessity of keeping it at a distance from fire or light on account of the inflammability of its vapour, although the neglect of such a precaution has before now cost an unfortunate patient her life. This precaution is brought prominently forward by Martindale, and is also mentioned in the American Pharmacopoia. These are only a few examples from a very large number, and the constant occurrence of directions for preparing substances which no medical man is ever likely to prepare not only makes the work more bulky, but is an actual annoyance to many men who consult it and find there the presence of so much that they do not want, along with the absence of what they do want. It might therefore be suggested that a useful alteration in the new edition of the Pharmacopaia would be to omit directions for the preparation of substances which are never prepared by medical men or by dispensing chemists, and at the same time to give: fuller directions than at present for the proper keeping of medicines, so that they may not lose their efficacy or become actually harmful by keeping in stock, although originally they may have been perfectly good.

As the Pharmacopoia is intended as a guide whereby the nature and composition of substances to be used in medicine may be ascertained, it is only fair on the part of the medical practitioner, for whose benefit it has been compiled, to ask that it should give certain directions as to the result of mixing various drags. Thus, under the headings of perchloride of iron and iodide of potassium we find long descriptions of their mode of preparation, but there is no suggestion that the practitioner who combines these two ingredients for the benefit of a rheumatic and anæmic patient will get free iodine produced by the mixture, and thus, in all probability, irritate the stomach of his patient. It is natural also that he might like to know that borax, although it has got a faintly alkaline reaction, may act as an acid, and that the mixture of glycerine of borax and bicarbonate of sodium may cause such effervescence as to blow, out the cork or burst the bottle either in the patient's pocket, or in transit through the post, to the great damage of Her Majesty's mails. A similar remark may be made about the subnitrate of bismuth. It is quite fair to expect a man to know that if he mixes bicarbonate of sodium with a strong solution of sulphate of magnesium he will very likely convert the whole into a paste, for these drugs have been in use for centuries; but a table of solubilities would be most valuable, not only in the case of remedies of recent introduction, but of old remedies where the solubility of unusual compounds is not known so well. One may know in a general way that alkaloids are precipitated by tannin, but it is almost impossible for anyone to be certain, without actual experiment, whether the tannin in a vegetable infusion will be sufficient to precipitate a small quantity of an alkaloid. For example, most men do not know whether the strychnine out of ten drops of tincture of nux vomica will be precipitated by the tannin in an ounce of infusion of gentian, nor can this knowledge be obtained from ordinary textbooks. A body such as the General Medical Council, entrusted with the preparation of the Pharmacopoia, is the proper body to have experiments made to settle such questions.

Another important point in solubility, and one which would be very useful were the Pharmacopoeia to give it, is the quantity of various substances contained in cold water after they have been once dissolved by heat; for example, sulphonal dissolves in 500 parts of cold water and in 15 of hot ; but I cannot find any information as to whether a quantity of it remains in solution after it has once been dissolved, or whether it all separates out on cooling. The same informa- 
tion regarding other solvents would be very useful. Thus, Squire mentions under the head of Compound Tincture of Chloroform that "The original British Pharmacopoia instructions read, 'dissolve the hydrochlorate of morphine and oil of peppermint in the spirit,' and when it was discovered that it would not dissolve, the word was changed to 'diffuse,' but by gently warming the three together a solution is at once obtained which does not precipitate on the addition of the other ingredients.'

A second useful alteration in the Pharmacopxia, then, would be the introduction of a very complete table of solubilities, not only of substances actually contained in the Pharmacopoia, but of those likely to be formed by admixture with other drugs, and also of the amount of substances which remain in solution in a cold solvent after they have once been dissolved by heat.

But one of the great advantages, and perhaps the chief advantage. which the two books I have mentioned possess over the British Pharmacopoeia, is that they give the practi tioner some idea of how to administer the medicine he desires in a form in which it can be taken by the patient. On looking up copaiba, for example, we find no directions regarding its administration in the Pharmacopxia, except that its dose is $\frac{1}{2}$ to 1 drachm, and the directions regarding the oil are equally scanty. The probability is that the practitioner who trusted entirely to the British Pharmacopocia for his preparations of the drug would administer either the one or the other in a form that his patient could not or would not take, so that the patient would either fail to be cured or would go to seek advice elsewhere. In Squire's Companion, on the other hand, we find ample directions for covering the disagreeable taste, and also the information that both balsam and oil can be put into capsules. It would be a great boon both to practitioner and patient, if the new edition of the Pharmacopaia could utilise some of the space which might be gained by cutting out useless directions for making drugs by putting in useful directions for prescribing them. Such directions are becoming all the more necessary on account of the old system of apprenticeship falling into disuse and of many men writing out prescriptions which are dispensed by the chemist instead of dispensing their own medicines. The practical knowledge which medical men formerly gained, either in the course of their apprenticeship or by making up medicines in their own dispensary, enabled them to put together mixtures which were by no means unpalatable to the patient. But one who simply prescribes is handicapped by not knowing whether the components of his mixture will not produce a heavy precipitate, a disagreeable colour, or an abominable taste, and he has no chance, like the dispenser of his own medicines, of rectifying his mistake when the medicine is made up, for it goes direct to the patient instead of being seen. tasted, and approved of by the doctor himself. It is to a great extent in consequence of these difficulties that so many proprietary preparations are now prescribed because such preparations, containing, as many of them do, useful drugs, are made up in such a way as to be not unpleasant, even if not actually agreeable to the patient. It would be a great benefit to the prescriber if the General Medical Council were to help him in his difficulty, and give him some directions to guide him in the way of making his medicines agreeable. We have already in the Pharmacopoia several syrup intended for this purpose. but we might have also an elixir, such as that of the United States Pharmacopoia, and perhaps other aids as well.

But it is often almost impossible to make the taste of medicines agreeable, and if they are in solution the patient feels on his palate the full force of their disagreeable taste. The only way of getting over this difficulty is to give the medicine in the form of a pill or capsule or cachet. We have in the Pharmacopoia no mention whatever of wafers or cachets, nor are capsules official, although all these are most useful aids in the administration of disagreeable medicines. Their introduction would surely be a step in the right direction.

Another complaint that patients make when the pills of the Pharmacopoia are prescribed (dosed as most of them are to 5 grains) is that the pills are so large that they cannot swallow them. It might be worth while for the Pharma- copœia Committee to consider whether it might not be advantageous to increase the standard strength of the pill mass so that $2 \frac{1}{2}$ grains at the outside would be a sufficient dose. But even pills of $2 \frac{1}{2}$ grains are comparatively large, and many people will swallow granules the size of a pin's head when they will not take a pill. Especially is this the case with children and with people who are much away from home, and who object to carrying bulky medicines in their pockets. In this respect the preparations of some of the French pharmacists are worthy of imitation. These consist of small granules of sugar of milk, each the size of a pin's head, each containing a definite dose of a powerful medicine, such as half a milligramme ( of a grain) of strychnine or atropine, or a milligramme ( ${ }^{2} 3$ of a grain) of arsenious acid, digitaline or morphine. As a means of prescribing active medicines these granules are most convenient, and the only disadvantage is that people may mistake them for homœopathic medicines to their own great disadvantage. Thus, a patient for whom I prescribed arsenic in this form thought the granules so innocent-looking that he took more than 1 advised him, and in ten days came back with well-marked symptoms of arsenical poisoning. These granules are, of course, only adapted for the administration of powerful drugs in small doses, and such drugs are already beginning to be much used in the form of small compressed tabloids, which can either be taken internally or dissolved in a drop or two of water, and injected hypodermically. The use of such tabloids obviates one of the great difficulties of hypodermic injections, namely, the tendency to decompose, or to alter in strength. They also afford a ready means of measuring out the dose accurately. The larger tabloids, such as those of soda-mint, are also so convenient for carrying about, that it would be useful to have something of this sort also in the new edition of the Pharmacopaia.

Besides omitting the descriptions of things that are not made by medical men or dispensers, the new Pharmacopoia might be improved by the revision of the directions for things that might be made. Thus, under the head of cataplasma conii, we find that an ounce of hemlock juice is to be evaporated to half its volume, and this mixed with half a pint of boiling water and a quarter of a pound of linseed meal. I have never made this poultice myself, nor do I know of anyone who has ever made it, but if such a poultice has been made, it would be interesting to learn who evaporated the hemlock juice and who made the poultice, because if the chemist evaporated the juice and made the poultice it would be cold before the patient got it, and if the juice were evaporated at home there would probably be no proper dish to evaporate it in. Any ordinary person would simply have used a little less boiling water or a little more linseed meal and left the hemlock juice without evaporation.

The enema assafœetidæ is one of the most useful remedies in the whole Pharmacopxia, but probably it is very rarely indeed made by the pharmacopœial method. Instead of the assafœtida being rubbed up with distilled water, a little of the tincture is simply mixed with the water and the mixture injected.

Although such an innovation would be warmly welcomed by many a medical man it is, perhaps, too much to hope that in the forthcoming edition of the Pharmacopocia we should find some indication of the actions of medicines such as are contained in the two other works I have already mentioned. But in regard to dosage it would certainly be a distinct advantage if the maximum quantity to be given in a day was indicated, as well as that for each individual dose. It might also be made compulsory, as in the German Pharmacopoia, for the medical man, when prescribing a quantity larger than the ordinary, to indicate the fact that he is aware of what he is doing by drawing the chemist's attention to this by means of a mark of exclamation. This proceeding necessarily lessens the risk of the patient getting an overdose by misadventure on the part of the prescriber.

It is very easy to suggest alterations in the Pharmacopæra; it may be very difficult to carry such suggestions into practice. Those I have made, even if they should be approved, cannot be carried out without the employment of skilled labour, and much experimental work necessitating the expenditure of a good deal of time and of money. Yet what 
body can do this so well as the General Medical Council? And if it can produce a Pharmacopxia better than any other existing one, the medical profession, not only in the three kingdoms but over the world-wide British Empire will repay its labours with gratitude.

\section{A REPORT}

ON THE

\section{POSSIBLE CONVEYANCE OF CERTAIN WATER-} BORNE DISEASES, ESPECIALLY TYPHOID FEVER, BY OYSTERS AND OTHER

\section{MOLLUSCS.}

\section{III.}

Sewage on Oyster Beds.-The Essex Coast Oyster Fisheries.

THE access of crude sewage to oyster beds constitutes a standing danger, although years may pass without any actual or recognisable injury resulting, for the presence of enteric evacuations, the vitality of the microbes, and their retention in the body of the animal or in the water enclosed between its valves are doubtless indispensable. A difference, however, should be made between breeding grounds and fattening beds, for if the oysters have been laid out for several months remote from all chance of defilement, it matters little under what conditions they were prior to their removal. This distinction, however, is not strictly observed in practice, the breeding ground being frequently resorted to for supplying the demands of excursionists and other less fastidious customers.

These remarks apply especially to the Essex coast, the favourite resort of Londoners of the middle class. The estuaries of the Deben, the Orwell, the Stour, the Colne, the Blackwater, and the Crouch are tidal reaches out of all pro. portion to the volumes of the rivers, and receiving the more or less crude sewage of towns with populations up to 35,000 and 60,000 . The Colne, one of the smallest, takes the sewage of Colchester, and provides one of the largest breeding grounds, although the deposition of sewage on the foreshores is palpable. Brightlingsea, the centre of the fishing industry, stands at the mouth of St. Osyth's Creek. Here a biological station was established last summer but had to be moved to another point, for though in close proximity to the oyster beds, the foulness of the water was such that few marine forms could live in it. It is true that these oysters are not sent up to London until they have been laid down elsewhere, but the "Colchester native" is not usually offered to the ordinary excursionists. The best fattening beds for Colne-bred oysters are in the Pyfleet, or the strait between Mersea Island and the mainland. Unless, perhaps, at its eastern mouth, opposite Brightlingsea, there can be no question of pollution here, for it is really an arm of the sea, and receives no drainage from either side.

So much cannot be said of the beds at Tollesbury; the crude sewage of Maldon is discharged ten miles higher up, but the conditions of the Blackwater are such as to exclude all thoughts of self-purification. Still more open to suspicion are the famous beds of Burnham-on-Crouch, the produce of which is esteemed as scarcely inferior to that of Whitstable. Burnham, though little more than an overgrown village, has had its full share of typhoid, and a sewer discharging between oyster beds on either side. The sewage, received in a sort of catchpit, is supposed to filter upwards through sand to the pipe sewer, in which it accumulates while the rising tide closes a valve which opens during the ebb. But apparently with a view to superseding the necessity for cleaning the filter, direct communication was some time ago opened up between the tank and the outfall sewer hy pipes laid in the bed of the filter, until the sewer was nearly, and if the valve had not been defective would have been completely, closed with sludge. It is worthy of note that during the past season the cases of typhoid fever in this district have been chiefly among dredgers and others engaged in the oyster fishery. Again there is considerable fishery carried on along the coast, and at Southend there is a common practice to moor the oyster boxes to the pier or a groyne while awaiting sale. In the sear 1890, when 340 cases of enteric fever occurred in the town up to the end of October only, a well known local practitioner declared that he had fished up fæcal masses within a few feet of such boxes. Enteric fever is, indeed, endemic in the place, and, so far as we can get at the facts, there were last year over 120 cases, a few of which were alleged to be "imported," but how many more were "exported," that is, went home during the incubation period or early stage of the disease, there are no means of knowing.

\section{THE ANTITOXIN TREATMENT OF DIPHTHERIA.}

\section{THE AGE MORTALITY OF CASES OF DIPHTHERIA} TREATED WITH ANTITOXIN.

Fon comparison with the table published in the BrITIsH MEDical JodRnAL of January 19th, giving the deaths at various ages of the cases of diphtheria treated with antitoxin reported by Professor Widerhofer and Dr. Goodall, we have looked through all the similar cases which have from time to time been reported in our pages, down to and including the issue of January 26th, and have tabulated the results in like form. The following is the result:

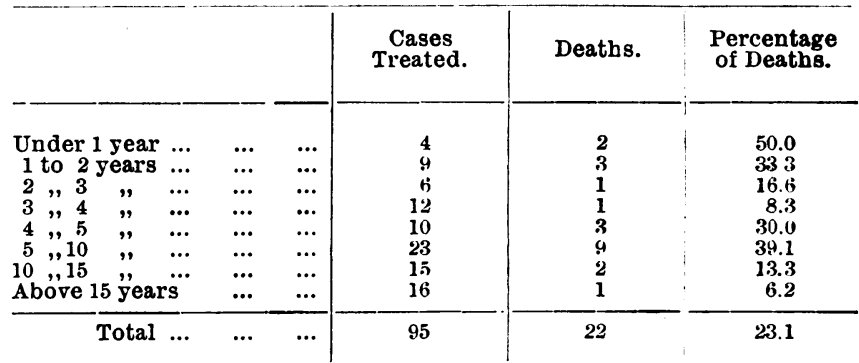

Professor Widerhofer's totals give a mortality of 24 per cent., Dr. Goodall's of 19.4 per cent, and the total of the various cases reported at different times in the JounNaI a mortality of 23.1 per cent.

No one of the three groups of cases is, however, sufficiently large to be of much value in regard to age mortality, but it certainly is rather surprising to note the very heavy loss of life among the general cases at ages between 5 and 10 , amounting to 39.1 per cent., compared with the very trivial mortality at that period of life in Widerhofer's and Goodall's cases, namely, only 5.4 per cent.

XXXVIII.-Dr. Ewart Duthrr, Resident Physician, Aberdeen City Hospital, sends in the following report of a case under the care of Dr. Matthew Hay :

J. K., aged 41 years, was admitted with diphtheria on December 24th, 1894, being the second day of the disease. $\mathrm{He}$ was a strong, well-nourished child, and presented on admission the following symptoms: On both tonsils a yellowish patch, throat reddened, breathing slightly impeded, croupy cough, and glands at the angle of the jaw slightly enlarged. Temperature $99^{\circ} \mathrm{F}$., pulse 120 , respiration 30 . The same evening a culture was taken from the throat; a poultice was applied to the neck, and tr. digitalis $\mathrm{mij}$, tr. ferri perchlor. miij prescribed three times daily. The throat was sprayed and brushed with a gargle consisting of pot. chlorat., liq. calc. sacch., ess. menth. pip., and glycerine. Next morning the patches on the throat were somewhat reduced in size, but the breathing was still impeded; pulse 116 , respiration 24 , temperature $97^{\circ}$. At 4.15 P.M. 3 jss of Klein's antitoxin was injected into the back with due antiseptic precautions. On the following day, at 5 A.M., the breathing was much distressed, the alæ of the nose acting, and there being recession of the lower intercostals; pulse 140 , respiration 28 , temperature $98^{\circ}$. An emetic dose of vin. ipecac. was administered, which was followed by vomiting and some relief of breathing. At $10.30 \mathbf{A . M}$. the breathing was more impeded, sibilant in character, croupy cough, lips and cheeks much cyanosed; pulse 115 , respiration 25. At 2 P.M. dyspnœa very urgent, pulse small, and very fast, 172 ; and tracheotomy was immediately performed, with relief of breathing. At 4 P.M. the 